ACTIVITAS

NERVOSA

CASE STUDY

SUPERIOR

\title{
How Long Can We Treat a Patient With the Same ANTIPSYCHOTIC DRUG? RESULTS FROM AN OUTPATIENT PSYCHIATRIC PRACTICE IN PRAGUE
}

\author{
Oldrich Vinar \\ Private Psychiatric Practice, Prague, Czech Republic \\ Received September 12, 2008; accepted October 10, 2008
}

\begin{abstract}
This report attempts to find a successful antipsychotic drug using duration of administration in routine private out-patient practice as a measure of success. All medical records of 56 schizophrenia patients over a ten-year period were examined. The antipsychotic drugs prescribed for longer than 4 years were identified. One patient was treated with clozapine for 31 years. Of the second generation antipsychotics, sertindole was most frequently prescribed for the longest periods: two patients for 9 years, one for 8 years, two for 7 years and six for 5 years. This was followed by risperidone with 4 patients treated for 5 years.
\end{abstract}

Key words: Antipsychotic drugs, Effectiveness, Treatment duration, Clozapine, Sertindole, Risperidone

\section{INTRODUCTION}

A plethora of methods is available when trying to estimate, and measure, the effectiveness of pychotropic drugs. Frequently, it is difficult to apply the results of randomized double-blind clinical studies to naturalistic conditions. This is due in particular to the selection of patients who must comply with the strict study criteria. Thus patients who have the classic presentation of the disorder are often excluded (Janicak, 1999).

The design of the CATIE study was closer to "real world“ conditions (Lieberman et al., 2005). The time to discontinuation of treatment was used to compare the effectiveness of 5 antipsychotic drugs. Within the 18month period, the frequency of discontinuation of olanzapine was lower than for risperidone, quetiapine, perphenazine or ziprasidone.

Haro et al. (2006) used antipsychotic discontinuation rates as an indicator of medication effectiveness in a threeyear prospective study in schizophrenia out-patients in 10 European countries. From 7728 patients, medication discontinuation ranged from $34 \%$ to $36 \%$ for clozapine and olanzapine respectively. Patients on quetiapine, risperidone, amisulpride and on first generation antipsychotics discontinued more frequently than those on clozapine or olanzapine.

\section{METHOD}

All medical records of patients fulfilling the criteria for the diagnosis of schizophrenia (F 20 according to ICD 10) treated in the author's private practice over the ten-year period (30 June 1996 to 30 June 2006) were examined. The drugs prescribed to these patients for periods longer than 4 years were identified.

\section{RESULTS}

In the 10-year period, 305 patients were seen by the author in his out-patient practice. Of these, 56 suffered from schizophrenia (F 20), as defined by ICD 10.

One patient took clozapine for 31 years. In 1973, he was admitted to the Psychiatric hospital with an acute hallucinatory paranoid syndrome. He was treated with clozapine up to $600 \mathrm{mg} / \mathrm{day}$. The florid psychotic symptoms subsided after 6 weeks when he was discharged. 
He never achieved perfect insight (persecutory delusions related to the past). Nevertheless, it did not interfere with excellent social adjustment and work as an architect. The dose of clozapine was reduced gradually. Even after 10 months after discharge from the hospital, the patient insisted on taking $25 \mathrm{mg}$ clozapine at night. Attempts to substitute hypnotics or other antipsychotics for clozapine failed. In 2004, he retired, moved out of Prague and the contact with him was lost.

Except this case, sertindole was found to be the antipsychotic taken for the longest periods: in two patients for 9 years, in one for 8 years, in two for 7 years and in six patients for 5 years. This was followed by risperidone with 4 patients treated for 5 years. Characteristics of the patients can be seen in the table No 1.

Table 1. Duration of treatment by selected drugs.

\begin{tabular}{|lcc|}
\hline gender born & $\begin{array}{c}\text { treatment } \\
\text { duration }\end{array}$ \\
\hline & & with Sertindole \\
\hline F & 1935 & 9 \\
F & 1956 & 9 \\
M & 1957 & 8 \\
M & 1976 & 7 \\
F & 1952 & 7 \\
F & 1948 & 5 \\
M & 1979 & 5 \\
F & 1973 & 5 \\
F & 1952 & 5 \\
F & 1979 & 5 \\
\hline & & 5 \\
\hline F & 1952 & 5 \\
M & 1963 & 5 \\
M & 1951 & 5 \\
F & 1956 & 5 \\
\hline
\end{tabular}

\section{Dose}

The dose of sertindole ranged from 4 to $24 \mathrm{mg} /$ day, and from $2-5 \mathrm{mg} /$ day for risperidone respectively. The dose was adjusted to fluctuating symptomatology, exacerbations could be managed at the prodromal stage, with hospitalization unnecessary. Most of the patients could work, although two patients only on a lower level of their professional qualification (e.g.

the doctor worked in the laboratory and did not treat patients).

\section{Concomitant medication}

SSRIs were used in 7 of the 11 patients on sertindole and in all risperidone patients, often repeatedly. Alprazolam was temporarily used by 9 patients on sertindole and in the 4 patients on risperidone. Mild depression with anhedonia and/or/anxiety was usually the reason for the prescription of these drugs.

\section{Choice of the antipsychotics}

The treatment with sertindole was not started more frequently than the treatment with other second generation antipsychotics in the years 1998-2002 when risperidone and olanzpine could compete in the duration of treatment: 21 patients were started on sertindole, with 34 on risperidone and 26 on olanzapine respectively. The other second generation antipsychotics were introduced to the Czech market in 2003 or later (Table No 2).

\section{Frequency of visits}

The frequency of visits of patients on sertindole and on risperidone to the author's practice did not differ from that of patients on other drugs (once every 2 to 9 weeks). Nor was the frequency of telephone calls from patients to the author any higher than those on other drugs.

\section{Adverse effects}

For sertindole the adverse effects were ephemeral (sleepiness, mild akathisia, nasal congestion, dizziness) with the exception of an increase of the body weight of 2 -6 kilograms in all patients. In one patient, mild diabetes of the II type appeared in the seventh year of sertindole administration (her mother also suffered from diabetes). Mild extrapyramidal rigidity, akathisia, dizziness, body weight increase and hyperprolactinaemia were seen in all patients treated with risperidone.

\section{DISCUSSION}

The individual patient who was treated with clozapine for 31 years raises the question of dependence on the drug. According to the author's experience this case is not unique. On rare occasions, it is difficult to finish clozapine administration, since the patient wishes to continue despite the frequent obligatory blood tests. Nevertheless, the diagnosis of dependence is not justified as they do not increase the dose and they do not experience any craving. Zapletalek et al. (1980) came to a comparable conclusion. 
The data obtained by this post hoc examination of medical records of the authors private out-patient clinic shows that sertindole was used by most patients for the longest time. This is not unequivocal evidence that sertindole is the best option, since the choice of antipsychotic was not randomized. Perhaps at pretreatment, the sertindole patients differed in some aspect However, the author tried in vain to find any reason for choosing sertindole for patients who, afterwards, took it for the longest time periods.

Table 2. Years when the drugs were launched in the Czech Republic.

\begin{tabular}{|ll|}
\hline Name & Year \\
\hline clozapine & 1973 \\
risperidone & 1995 \\
olanzapine & 1997 \\
sertindol & 1998 \\
quetiapine & 1999 \\
amisulpride & 2001 \\
ziprasidone & 2001 \\
zotepine & 2004 \\
aripiprazol & 2005 \\
\hline
\end{tabular}

It is difficult to interpret the possible influence of the temporary withdrawal of sertindole from the market. The author was allowed to continue the treatment by the Czech authorities (State Inst. for the Drug Control) under the condition of monthly ECG recordings. No prolongation of the QTc interval was found, it never exceeded $450 \mathrm{msec}$.

At $18.4 \%$, the author's out-patient clinic has a higher proportion of schizophrenic patients than other clinics in the Czech Republic (15.3\%, ÚZIS, 2006). Due to the authors past research work in the area, doctors refer schizophrenic patients more frequently to him. Since the patients and their relatives know the reason for the referral, the patients may trust the author more and comply more with his advice.

The number of university graduates $(\mathrm{N}=8)$ among the 11 patients treated with sertindole was higher than in other author's patients. It could represent a bias, since better education could contribute to a better understanding of the goal of the treatment, better therapeutic relationship and better compliance.
The long duration of treatment with sertindole might be related to the good tolerance (minimal sedation, practically non-existent extrapyramidal symptoms) (Kasper, 2002) and favourable effect on cognitive functions (Hale, 2002).

The importance of the study is the demonstration that retrospective exploration of data in the records of outpatients is feasible, when trying to find differences in the effectiveness of antipsychotic drugs, using time to discontinuation as the criterion. The strict naturalistic setting and the long time of follow-up contribute to the validity of the study.

Randomized prospective studies introduce an aspect of scientific artificiality to the therapeutic practice. E.g. the patient cannot ignore the procedure of informed consent. He is aware of another motivation of the doctor than just to help in his suffering. The consequences for the doctorpatient relationship might be greater than acknowledged. The reliability of retrospective studies might be lower compared to randomized prospective studies - this disadvantage is compensated by the fact that they reflect clinical reality.

\section{REFERENCES}

Hale, A. (2002). Sertindole: a clinical efficacy profile. International Journal of Psychiatric Clinical Practice, 6 (suppl. 1), S21-26.

Haro, J.M., Snarez, D., Novick, D., Brown, J., Usall, J, Naber, D., \& the SOHO Study Group (2007). Three-year antipsychotic effectiveness in the out-patient care of schizophrenia: Observational versus randomized studies results. European Neuropsychopharmacology, 17, 235-44

Janicak, P.G. (1999). Handbook of Psychopharmacotherapy. Philadelphia: Lippincott Williams and Wilkins, pp.391.

Kasper, S. (2002) Sertindole: safety and tolerability profile. International Journal of Psychiatric Clinical Practice, 6 (suppl. 1) S27-S32

Lieberman, J.A., Stroup, T.S., McEvoy, J.P., Swartz, M.S., Rosenheck, R.A., Perkins, D.O., Keefe, R.S., Davis, S.M., Davis, C.E., Lebowitz, B.D., Severe, J., \& Hsiao, J.K. (2005) Effectiveness of antipsychotic drugs in patiens with chronic schizophrenia. New England Journal of Medicine, 353, 12091223

ÚZIS - (Ústav zdravotnických informací a statistiky) (2006). Czech Health Statistics Yearbook 2005. Prague 2006. pp. 262 Zapletalek, M., Preiningerova, O., \& Hanus, H. (1980). Verursacht Clozapin eine Abhängigkeit? Agressologie, 21 (suppl. A), 19-22. 